\title{
A HOSPITAL PHARMACOPOEIA OF THE NINETEENTH CENTURY
}

\author{
by
}

\section{S. T. ANNING}

MATTHEws wrote: 'The compilation of a pharmacopoeia by the physicians and the apothecaries of a hospital proved a great convenience to the many resident and consulting physicians treating patients there. Prescriptions in regular use for the treatment of a particular set of symptoms constituted the bulk of the formulae. Time could be saved by merely writing the name of the mixture or pills, etc., required and a supply for stock could be prepared beforehand. . . . As early as 1730 St. Bartholomew's Hospital, London, had its own printed pharmacopoeia, and, as newly established hospitals adopted their own routines for the dispensing of the medicines ordered for their patients, so the number of hospital pharmacopoeias increased'.1

At the General Infirmary at Leeds the earliest pharmacopoeia to be discovered is that of 1863. It is hand-written and the calligraphy throughout is the same but additional entries, presumably later, are in a different hand. There are marginal initialed notes which were written by T.C.A., C.G.W., J.D.H., C.B. and another which is undecipherable. The initials must be those of Thomas Clifford Allbutt,* Claudius Galen Wheelhouse** and John Deakin Heaton***. C.B. has not been identified and was certainly not on the honorary staff of the Infirmary. The marginal notes must have been made between 1864, the year of publication of the first British Pharmacopoeia and of the appointments of Allbutt and Wheelhouse to the staff of the Infirmary, and 1880 when Heaton died.

In the Infirmary pharmacopoeia of 1863 there are three Aquae or medicated waters: Aqua Menthol Pip. [sic] with oil of peppermint and rectified wine, Aqua Sodae containing carbonate of soda and citric acid, and Aqua Camphorata containing copper sulphate, Armenian bole (a clay coloured red by iron) and camphor.

Hydrocyanic acid of two strengths is mentioned and there is a note signed by T.C.A. that it is dangerous to retain these. He advised that only the B.P. preparation be dispensed. There is also Acid. Nit. Mur. dil. containing equal quantities of dilute nitric and hydrochloric acids. A recipe for black ink follows.

There are six Cataplasmata or poultices. Two contain bread and the others oatmeal, quinine and camomile flowers, zinc sulphate and soap, and lead subacetate and zinc oxide, respectively. It is noteworthy that neither starch nor kaolin were used.

Cerata are usually mixtures of wax and oil used for external application. Four are given, one being made with soft soap, potash and precipitated chalk, the others with

* 1836-1925. Physician at the Infirmary 1864-84. Later Regius Professor of Physic at Cambridge. Probably the greatest physician of his time.

** 1826-1909. Surgeon at the Infirmary 1864-84. In 1886 he came top of the poll in the first election for a representative of the profession on the General Medical Council.

*** 1817-80. Physician at the Infirmary 1849-80. A well-known physician in Leeds, he played a major part in the foundation of the Yorkshire College in 1874 and he was its first chairman of the Council. 


\section{Texts and Documents}

wax and olive oil and the addition of either lead oleate and chalk, Armenian bole or calamine powder.

The Collyria (eye washes or drops) number three. Lead acetate, and aluminium sulphate with either potassium sulphate or zinc sulphate were used. Later additions to the list (undated) include one containing silver nitrate and another atropine sulphate, and there is a note initialed T.C.A.: 'Should these be called Collyria or Guttae?' After the collyria comes a cholera mixture containing tincture of opium, camphor mixture and tincture of ginger. It has been deleted and a note states 'not wanted at all'.

Confectiones were mixtures of a medicinal substance with honey, sugar or treacle and were similar to electuaria or electuaries. Four confections are mentioned containing, respectively, senna and sulphur, peroxide of iron, jalap, and potassium bitartrate.

Decoctions are made by boiling a medicinal substance in water and straining. Five are mentioned. The most complex is Decoct. Aloes Co. which contained extract of liquorice, potassium subcarbonate, aloes, powdered myrrh, coriander seeds and water. Others required guaiac and sassafras root, extract of haematoxylin and powdered ginger, leaves of chimaphila ('winter green'), or sarsaparilla root, liquorice, guaiac and sassafras root. The one containing winter green leaves was deleted by T.C.A. and C.G.W.

Of the five Electuaria two were described as diuretic; one containing potassium bitartrate, powdered liquorice, powdered squill and syrup, the other potassium bitartrate, powdered jalap and liquorice, and syrup of buckthorn berries. The other three contained combinations of sulphur, senna, jalap or black pepper. T.C.A. noted that the first two, the diuretic electuaries, were not now used but that the others should be retained.

There are six Emulsiones. The first contains sweet almond oil, white sugar and powdered acacia gum with distilled water. The second is similar but camphor replaces acacia. The third contains oil of cubeb and acacia gum, and the fourth is more complex having powdered tragacanth, white sugar, potassium nitrate, balsam of copaiba, nitric acid, spirits of lavender and water. The fifth only contains almond oil, syrup, potash and water. T.C.A. notes that it is frequently used and that the sixth should be retained not as a purgative but as a remedy in certain cases of diarrhoea. It consists of castor oil, powdered tragacanth, tincture of opium, syrup and cinnamon water.

The Enemata are also six in number and contain, respectively, decoction of barley; starch and tincture of opium; castor oil, mucilage and yolk of eggs; magnesium sulphate and decoction of oats; turpentine and yolk of eggs; tobacco leaves. As regards the last C.G.W. notes 'omit as dangerous' but T.C.A. adds 'may be useful.' Tobacco enema, made by infusing the leaves in boiling water, was considered useful in strangulated hernia, obstinate constipation and retention of urine. ${ }^{2}$

Of the Emplastra two consisted of soap and mercury compounds, and one of these, known as 'Scott's Plaster', is noted by T.C.A. as being much used. The other two plasters were made, respectively, of cantharides plaster with Burgundy pitch, and wax, yellow resin, turpentine, olive oil and powdered cantharides. 


\section{Texts and Documents}

To the five Gargarismata, which contain chiefly hydrochloric acid and rose water, rose water alone, perchloride of mercury and decoction of quinine, alumina and decoction of quinine, or borax and honey, were later added two more, both containing hydrochloric acid but with chlorate of potash in one and honey in the other.

There are six varieties of Guttae or drops, viz., belladonna, diuretic (with tincture of squill and colchicum), Guttae Hyd. Bichlor. Comp. (tincture of iodine, arsenic solution and perchloride of mercury), morphia, silver nitrate and morphia, and physostigmine (made with calabar beans and water). The recipe for silver nitrate and morphia drops has Mr. Nunneley's name attached* while a note at the side by C.G.W. states 'Should be retained. Very useful', and a further note by J.D.H. reads 'I don't understand it'. In Squire's Companion to the Pharmacopoeia there is a reference to the calabar bean, 'The ordeal bean of old Calabar' under 'Not Officinal'. It states: ' $\ldots$ its use in ophthalmic surgery has been developed by the labours of Dr. Pearce, Dr. Richardson, and Mr. Nunneley, of Leeds. The latter gentleman published several letters in the Lancet on the subject in $1863^{\prime} .^{3}$

Of the six Haustus or draughts two contain rhubarb and chalk and the others rhubarb and magnesium sulphate, oil of male fern, senna and magnesium sulphate, and the last, known as 'The House Mixture' or 'Black Draught' contains senna leaves, ginger, magnesium sulphate, extract of liquorice and peppermint.

An Infusum is made by steeping or extracting the active principles by pouring hot or cold water upon a substance or by letting it stand in hot or cold water. Nine infusions are described making use of the following substances:-catechu, gentian root, leaves of buchu (a South African shrub), petals of red poppies (made in two strengths), senna leaves, powdered nux vomica, matico leaves, and quassia. Opposite the prescription for Infus. Rosae Conc. are notes:- 'Is in B.P.'. 'No. This is a cheap imitation. Should be retained. T.C.A. J.D.H.' The Infirmary infusion contained dilute sulphuric acid, syrup of poppy leaves and water, whereas the B.P. version used rose petals.

A Julep is a sweet mixture made aromatic with a volatile oil. For example cardiac julep is described containing compound spirits of lavender, spirits of pimento and syrup of red poppy leaves. Another cardiac julep included spirits of cinnamon, tincture of cardamon, syrup and spirits of ammonia. There are five other juleps: Julep Sedativa (with julep nitros and dilute acetic acid), Julep Saline, Julep Alk. Vol. (nitrous spirits of ether, spirits of ammonia and bicarbonate of soda), Julep Nitros (potassium nitrate in water) and Julep Laxativ. (magnesium sulphate, tincture of cardamon and water). Juleps are not included in Squire's Companion. ${ }^{4}$

Under Linctus only two preparations are given, one containing mucilage, syrup of red poppy leaves and honey of squill, and the other confection of roses, powdered tragacanth compound, dilute sulphuric acid and spirits of papaverine. A side note suggests another linctus "with [a] small quantity of Morphia in it. Call it "Linctus Morph.”. C.B. T.C.A. C.G.W.'

The section on Linimentum gives eight examples of which two contain turpentine. There is also an iodine liniment, one containing soft soap and other substances, a liniment consisting of tincture of opium, liquid ammonia and spirit, another with

* Thomas Nunneley (1809-70) was a surgeon at the Infirmary from 1864 until his death. 


\section{Texts and Documents}

opium, chloroform and soap liniment, and lastly one which was a mixture of olive oil and croton oil, and one which contained mercury liniment and powdered opium.

There are ten Lotions viz., Lotio Ammon. Acet., Lotio acid. Nit., Lotio ammon. Subcarb., Lotio Myrhh., Lotio Evaporans (containing lead solution, spirits and water), Lotio Frigida (liq. ammon. acet. in spirit), Lotio Kreosote, Lotio Nigra (chloride of mercury in lime water), Lotio Ammon. Mur., and Lotio Frigid. (ammonium chloride, potassium nitrate and water) which, it is stated, is to be used for strangulated hernia. After a few pages of notes in other handwriting a further list of nine lotions in the original script appears. These are Lotio Acid. Acet., Lotio Astringens (camphor, powdered opium, zinc sulphate and water), Lotio Rubra Conc. (zinc sulphate, tincture of lavender and water), Lotio Tannin, Lotio Acid. Hydrocyanic, Lotio Sodae Chlor., Lotio pro Ore (potassium chlorate and water), Lotio Sodae Carb., and Lotio Quinci (copper sulphate, Armenian bole, camphor and hot water) which a note states is 'not used at all now'.

The next page of entries shows a variety of preparations. The first is Liquor Strychnia (strychnia, dilute hydrochloric acid, spirit and water) followed by carbolic acid (one part with linseed oil 5 parts). The next is 'The Paste. Same as the above stiffened with Chalk'. The last is 'Carbolic Acid 1 part Water 20 parts as a Lotion'.

There are over forty Misturae. A mixture has been defined as a medicine composed of several liquids mixed together, or of a liquid containing solid matter in suspension, the liquids being intended for internal use. The mixtures shown are: Mist. Alk. cum Mag., Mist. Astringens (chalk and opium, spirits of pimento and cardiac julep), Mist. Cretae cum Rheo (including tincture of opium), Mist. Nit. Pect. (squill and julep nitros), Mist. Cinchonae, Mist. Acid. Morph. (morphine acetate and acetic acid), Mist. Copaiba, Mist. Ferri Co. (gum of myrhh, potassium carbonate, sulphate of iron, nutmeg oil, spirits of wine and water), Mist. Guaiaci, Mist. Gentian Co. (infusion of senna and gentian root), Mist. Liq. Potassae (syrup of white poppy capsules, spirits of nitrous ether, syrup of rhubarb, solution of potash and water), Mist. Mag. Carb., Mist. Acacia (mucilage and simple syrup. In note alongside: 'not required'.), Mist Mag. cum Opii, Mist. Creta Conc., Mist. Pectoral (treacle, acetic acid, tincture of opium and hot water), Mist. Scillae (syrup of white poppy capsules, nitrous spirit of ether, syrup of squill, tincture of camphor and water), Mist. Paregoric. (syrup of white poppy capsules and compound tincture of camphor), Mist. Potass. Iodid., Mist. Sodae Carbon. (contained syrup of white poppy capsules), Mist. Sodae Carb. (no poppy capsules), Mist. Senegae (decoction of senega root and tincture of squills), Mist. Syr. Rhei. (syrup of rhubarb and of white poppy capsules, etc.), Mist. Quinae Sulph. [sic] (Sulphate of quinine, sulphuric acid and infusion of roses. T.C.A. notes that the addition of oil of almonds improves it without costing much and adds ' $I$ also think it very desirable that our medicines should not look like water.'), Mist. Terebinth., Mist. Vini Ferri (iron wire, sherry, tincture of quinine and of cinnamon), Mist. Saline. Efferves. (carbonate of soda and distilled water), Mist. Vol. Efferves. Saline (ammonium carbonate and water), Mist. Acid. Citric., Mist. Saline Vol. (ammonium carbonate and citric acid), Mist. Bismuth. Co., Mist. Hydragogue (the sediment from the juice of the Squirting Cucumber fruit and syrup of Rhamnus Frangula), Mist. Mag. cum Rheo. (powdered rhubarb root and mist. mag. alk.), 
Mist. Acid. Nit. Mur., Mist. Mag. cum Mag. Sulph., Mist. Cascarillae Co. (squill, tincture of camphor and opium, and infusion of cascarilla), Mist. Guaiaci Ammon., Mist. Potass. Chlor. (chlorate of potash, syrup of white poppy capsules and nitrous spirits of ether), Mel Boracis, Mist. Diarrhoea Conc. (includes tincture of opium and of cardamoms), Mist. Acid. Hydrocyanic., Mist. Bismuth. Co., Dr. Allbutt's Mist. Bismuth. Co., and Dr. Allbutt's Mist. Bromide. The last two are in the same handwriting as the other entries but must have been added later as Dr. Allbutt was elected to the staff in 1864 .

Many pills are listed, most made with simple syrup but some with 'venetian soap'. They are: Pil. Aloes, Pil. Aloes cum Ferro, Pil. Cal. cum Antim. Tart. (calomel, opium and antimony tartrate), Pil. Galban, cum Zinci (galbanum is a gum resin), Pil. Hydrarg. Comp. (contained some powdered rhubarb), Pil. Ipecac. Co. (calomel, powdered ipecacuan and extract of poppy capsule), Pil. Ipecac. cum Conii (extract of hemlock and powdered ipecacuan), Pil. Rhei Comp. (rhubarb root, aloes and myrhh), Pil. Scillae cum Zinci, Pil. Pectoral (ipecacuan, squill and extract of hyoscyamus), Pil. Conii (extract of hemlock), Pil. Rhei cum Hydrarg., Pil. Aloes cum Assafoetid., Pil. Zinci Comp. (squill, hemlock and zinc sulphate), Pil. Hydrarg. cum Gent. (Pil. Hydrarg., extract of gentian and powdered rhubarb root), Pil. Hydrarg. Aper. (Pil. Hydrarg., hyoscyamus and colocynth fruit), Pil. Aperientes (Mr. Nunneley's) (aloes, jalap and calomel), and Pil. Hydrarg. cum Ipecac. (Mr. Nunneley's).

There are only a few powders but some have odd names: Pulv. Alterans (rhubarb, mercury with sulphur and guaiac), Pulv. Angelic. (mercuric nitrate and alumina), Pulv. Aperiens (rhubarb, chalk and cinnamon), Pulv. Bismuth. Co. (bismuth nitrate, rhubarb and hemlock), Pulv. Cardiac. (ginger, black pepper and liquorice), Pulv. Card. cum Alk. (bicarbonate of soda, ginger, calumba, the root of a climbing plant from Mozambique, and gentian), Pulv. Coccicens (potassium nitrate and Armenian bole), Pulv. Prophylact. (rhubarb and soda), Pulv. Alum. Co. (alumina and kino), Pulv. Purgans (potassium sulphate and jalap), Pulv. Roborans (starch, Armenian bole and oil and wild marjoram), and Pulv. Alkaline [sic] (bicarbonate of soda and magnesium sulphate).

The solutions are four in number, one of carbonate of ammonia, one of citric acid and two containing magnesium sulphate in different quantities. These are followed by a single suppository containing opium with a note 'hardly necessary to retain this'. There are three syrups containing respectively rhubarb, senna and ginger, squill, and sarsaparilla.

The three tinctures are made with rectified spirits of wine and are Tinct. Colchici, Tinct. Iodine [sic] (which C.G.W. notes is inferior to that of the British Pharmacopoeia in not including potassium iodide), and Tinct. Camph. Co. which contained opium. It seems curious that there is no tincture of digitalis (or for that matter an infusion) included in the Infirmary's pharmacopoeia. Withering's An Account of the Foxglove had been published in 1785 . It suggests that the conservative physicians were slow to appreciate the importance of this drug though both the tincture and the infusion are included in the British Pharmacopoeia of 1864. It was probably on account of this that the up-to-date Allbutt did not have it added to the Infirmary's pharmacopoeia on his appointment to the staff in the same year. 
The Unguentum or ointment seems to have played a large part in treatment for there are many examples. Most contain lard, though olive oil or other oils are also employed. Those listed are: Ung. Antim. Tart. cum 0l. Croton., Ung. Arsenic., Ung. Cerae (yellow wax and olive oil), Ung. Cera Fort. (very similar), Ung Camph., Ung. Gallae (powdered galls and lard), Ung. Gallae Comp. (the same with lead and opium), Ung. Opii, Ung. Potassae Iod., Ung. Ophthalmic. (ammoniated mercury, zinc oxide and Armenian bole), Ung. Lyttae (cantharides and Ung. Resinae), Ung. Emoliens [sic] (lead plaster, wax and olive oil), Ung. Digestiv. Mit. (wax, linseed oil, turpentine and resin), Ung. Resinae Flava (the same as the last with less turpentine), Ung. Ferri Carb., Ung. Rubrum (olive oil, wax and Armenian bole), Ung. Sulphur., Ung. Hyd. cum Pice, Ung. Hyd. Nit. Mit. cum Zinco, Ung. Zinci Sulph., Ung. Pavonis (sulphur and lard), Ung. Zinci Chlor., Ung. Sulph. Precip., and Ung. Guthrie (silver nitrate, powdered opium and lard).

In addition to digitalis there are several other useful drugs or substances included in the British Pharmacopoeia of 1864 but not in that of the Infirmary of 1863. Aconite, cannabis indica, capsicum, ergot, lobelia, cod liver oil, podophyllum, santonin and stramonium may be mentioned. The responsibility for these omissions must rest on the honorary medical staff in 1863. Of the physicians Dr. Charles Chadwick was senior. He was then 48 and had been on the staff since 1842. Dr. John Deakin Heaton was two years younger and had been a physician at the hospital for 14 years. The third, Dr. Robert George Hardwick, was only 29 in 1863 and had been appointed three years before, but he was a sick man and died in 1864. Two of the surgeons, Mr. Samuel Smith and Mr. Thomas Pridgin Teale, F.R.S., had achieved eminence but in 1863 they were respectively 73 and 62 years of age and about to retire. The third, Mr. Samuel Hey a grandson of William Hey, F.R.S., was 48. He appears to have lacked the initiative and drive of his distinguished forebear. If Allbutt, Pridgin Teale Jr., Wheelhouse and Nunneley, all appointed in 1864, had been responsible for the Infirmary's pharmacopoeia it would have been better but the advent of the British Pharmacopoeia made its deficiencies of little importance.

\section{REFERENCES}

1. Matthews, Leslie G., History of Pharmacy in Britain, Edinburgh and London, E. \& S. Livingstone, 1962, p. 102.

2. SQUIRE, Peter, A Companion to the British Pharmacopoeia, London, 1864, p. 185.

3. SQUiRe, Peter, ibid. p. 38.

4. SQUIRE, Peter, ibid. 